\title{
Representações Sociais de Mulher Cigana entre População Não-Cigana Brasileira e Italiana: Ancoragem Psicológica e Social
}

\author{
Mariana Bonomo ${ }^{1}$ \\ Universidade Federal do Espírito Santo \\ Giannino Melotti \\ Università di Bologna \\ Monica Pivett \\ Università di Chieti-Pescara
}

\begin{abstract}
RESUMO - Referenciados pela abordagem não consensual da Teoria das Representações Sociais, objetivou-se investigar os processos de ancoragem psicológica e social frente às representações sociais de mulher cigana, o que permite analisar a modulação dos objetos sociais a partir do posicionamento interindividual e das experiências compartilhadas pelos sujeitos da representação segundo seu contexto sociocultural de inserção. Participaram do estudo 643 sujeitos não ciganos, brasileiros e italianos, com idade média de 22,81 anos ( $\mathrm{DP}=5,73$ ). Aplicando a análise de correspondência lexical, o processo de ancoragem psicológica indicou a formulação de oito clusters, que caracterizam diferentes representações, segundo as dimensões: mágicoreligiosa, maternidade e cuidado com o grupo-família, exclusão social e figuras do feminino. Por meio da análise do processo de ancoragem social, verificou-se que variáveis como contato, sexo e nacionalidade atuam na modulação dessas diferentes representações sobre o objeto, produzindo ambiguidades que, historicamente, têm orientado processos de discriminação contra grupos ciganos.
\end{abstract}

Palavras-chave: mulher cigana, processos de ancoragem, representações sociais

\section{Social Representations of the Gypsy Woman among Non-Gypsy Brazilian and Italian Population: Psychological and Social Anchoring}

\begin{abstract}
Based on the non-consensual approach of the Theory of Social Representations, the present study aimed to investigate the processes of social and psychological anchoring regarding the social representations of the gypsy woman, dimension which allows analyzing the modulation of the social objects from the interindividual positioning and the experiences shared by subjects of the representation according to their sociocultural context of insertion. The study included 643 non-gypsy, Brazilian and Italian individuals with mean age of 22.81 years ( $\mathrm{SD}=5.73$ ). Once lexical correspondence analysis was conducted, the process of psychological anchoring indicated the formation of eight clusters, which characterize different representations, according to the following dimensions: magical-religious, maternity and care of the family-group, social exclusion, and female figures. Through the analysis of the social anchoring process, we verified that variables such as contact, gender, and nationality act in the modulation of these different representations over the object, producing ambiguities that have historically led to processes of discrimination against gypsy groups.
\end{abstract}

Keywords: gypsy woman, anchoring processes, social representations

Representando os ciganos na generalidade, as mulheres ciganas têm sofrido múltiplo preconceito, em função da pertença étnica, de gênero e do contexto de extrema pobreza em que muitos grupos ciganos se encontram, fenômeno também conhecido como discriminação interseccional, que reflete a convergência de múltiplos fatores na produção de assimetrias sociais e consequente processo de exclusão (Curran, 2016; Jovanović, Kóczé, \& Balogh, 2015; Oprea, 2009). Apesar da escassez de estudos sobre essa categoria social, os dados existentes informam que as mulheres ciganas sofrem mais discriminação do que as mulheres em geral e do que os homens ciganos em particular, posto que à sua

1 Endereço para correspondência: Programa de Pós-Graduação em Psicologia. Centro de Ciências Humanas e Naturais, Universidade Federal do Espírito Santo, Av. Fernando Ferrari, no 514, Campus Universitário Goiabeiras, Vitória, ES, Brasil. CEP: 29075-910. E-mail: marianadalbo@gmail.com imagem se ancoram significados historicamente revestidos tanto de misoginia quanto de anticiganismo (Hancock, 2008; Magano \& Mendes, 2014; Ravnbøl, 2010).

Apesar da reconhecida centralidade na manutenção e transmissão de sua cultura, as mulheres ciganas ainda enfrentam inúmeros obstáculos em função de uma sociabilidade estruturada em relações de gênero desiguais (Mendes, 2015). De acordo com Ceneda (2002) e Magano e Mendes (2014), em diversos grupos, o universo feminino encontra-se submetido ao controle dos homens, orientados por normas e práticas culturais que naturalizam o espaço da mulher a partir da esfera doméstica voltada aos cuidados da casa e da família, privando-as de inserção escolar, exercício de uma profissão, escolha do cônjuge, entre outros fatores que têm limitado a autonomia e liberdade dessas mulheres, sob a justificativa de alinhamento cultural (Ceneda, 2002; Jovanović et al., 2015). 
No contexto da experiência e do contato com os grupos não ciganos, se a elas se associam imagens romantizadas da dança e da alegria, também são discriminadas e estigmatizadas com os clássicos estereótipos de rogadoras de pragas, sujas, ladras e traiçoeiras (Bonomo et al., 2011; Moscovici, 2011). Esse imaginário agrava ainda mais o contexto de marginalização e oportunidades reduzidas à sua inserção social, realidade que tem sido identificada em diferentes territórios e nacionalidades, como Brasil e Itália, contextos de investigação do presente estudo.

Tendo em vista a tarefa de investigar como são representadas as mulheres ciganas, o estudo do fenômeno representacional a partir da investigação dos processos de ancoragem poderá contribuir para análise e aprofundamento da função de variáveis de tipo contextuais na produção e manutenção da construção desse objeto social. Ao analisar as forças sociais envolvidas nesse trabalho de elaboração do campo representacional, bem como de seu produto materializado na posição dos indivíduos, tem-se a possibilidade de identificar os elementos chaves para proposição de formas de se intervir na redução do preconceito e da discriminação social.

\section{A Questão Cigana no Brasil e na Itália}

Com população atual estimada em mais de dez milhões de pessoas pertencentes a diferentes etnias ciganas (Ram, 2014), pesquisas históricas informam que os ciganos saíram da Índia antes do ano 1000 e chegaram ao Irã entre os séculos IX e X d.C. (Lermo, Román, Marrodán, \& Mesa, 2006). A partir do Egito, Creta e Peloponeso, entraram no ocidente e se dispersaram através de diferentes rotas no continente europeu, especialmente ao longo do século XV, chegando à América do Sul em finais do século XVI sob o imperativo da execução de decretos de deportação que os caracterizavam como criminosos e ameaça à sociedade local (Moonen, 2011).

Em diferentes contextos e temporalidades (Moonen, 2011; Moscovici, 2009; Teixeira, 2008), os ciganos têm sido representados a partir de significados negativamente valorados, que vão desde a sua associação a estereótipos depreciativos (como ladrões, criminosos e portadores de maldições; Carvalho, Lima, Faro, \& Silva, 2012; Moscovici, 2011) a processos de desumanização e infra-humanização, afastando-os das sociabilidades reconhecidas como legítimas (Berti, Pivetti, \& Di Battista, 2013; Pérez, Moscovici, \& Chulvi, 2002). Como reflexo desse imaginário social, na atualidade, inúmeros episódios de banimento e práticas discriminatórias e de exclusão contra integrantes de grupos ciganos têm sido verificados, fortalecendo as relações de conflito entre os universos cigano e não cigano (Mendes, 2015; Pettigrew \& Tropp, 2006).

$\mathrm{Na}$ Itália, de acordo com Sigona (2006), os ciganos, que totalizariam cerca de 150 mil pessoas no país $(60 \%$ com cidadania italiana), ainda sofrem com processos de segregação e violências de diferentes ordens, como ausência de políticas públicas ou mesmo a existência de práticas institucionalizadas contra membros dessa etnia, que se refletem no seu isolamento político, econômico e cultural (Monaci \& Trentin, 2008). Em território brasileiro, por sua vez, a etnia ainda habita na invisibilidade (Teixeira, 2008), sendo recentes os esforços para elaboração de políticas públicas voltadas para essa população. De acordo com o relatório Brasil Cigano (Brasil, 2013), estima-se que vivam no Brasil mais de meio milhão de ciganos, a maioria ainda analfabeta e em situação de extrema pobreza, sem assistência médica, educacional e alimentar, bem como de recursos que valorizem seu modo de vida (Carvalho et al., 2012).

Tanto no Brasil quanto na Itália, nos mais diversos contextos geopolíticos e socioculturais, estudos desenvolvidos acerca do imaginário social sobre os ciganos informam que o preconceito generalizado permanece como dinâmica elementar dos resultados identificados (Berti, Pivetti, \& Di Battista, 2013; Bonomo et al., 2011; Sigona, 2006). De acordo com Tileagã (2015) e Lima, Faro e Santos (2016), nesse sistema de significação opera, sobretudo, uma exclusão moral tornando legítimas as diversas formas de violência e discriminação dirigidas aos povos ciganos. Para Doise (2002) e Jodelet (1999), esse diagnóstico social revela um paradoxo no interior das próprias sociedades contemporâneas, que se pretendem regidas pelos direitos humanos e ideais da democracia: como promover valores como justiça e liberdade tolerando e nutrindo práticas e políticas sociais institucionalizadas que geram e justificam a exclusão social contra determinadas categorias sociais?

Considerando a relevância de se conhecer as diferentes representações sociais da figura central de referência ao imaginário social sobre a etnia cigana, qual seja, as mulheres ciganas, a presente proposição se apoia na tarefa de investigar o referido campo representacional a partir das diferentes tomadas de posição de sujeitos não ciganos, italianos e brasileiros, frente ao objeto de representação social Mulher Cigana (Doise, 2011; Moscovici, 2009).

\section{Teoria das Representações Sociais e a Escola de Genebra}

A Teoria das Representações Sociais (Jodelet, 2015; Marková, 2000, 2006; Moscovici, 2003) é reconhecida como campo teórico-metodológico de grande relevância para a produção científica acerca dos diferentes objetos sociais. Há mais de cinco décadas, tem contribuído para a compreensão do pensamento social e da forma como os indivíduos e grupos sociais interpretam o mundo e constroem a realidade social.

A proposta teórico-metodológica da Escola de Genebra, conhecida como abordagem não consensual da Teoria das Representações Sociais, apoia-se na proposição das representações sociais como princípios organizadores de tomadas de posição individuais (Clémence, Doise, \& Lorenzi-Cioldi, 1994; Doise, 2011). Subjacente a esse quadro conceitual, três pressupostos relativos à dinâmica do fenômeno das representações sociais são formulados (Almeida, 2009; Laszlo, 1997; Rateau, 2004): (a) as representações sociais são compartilhadas socialmente no interior dos grupos sociais e sociedades; contudo, (b) frente a um mesmo objeto de representação, os indivíduos poderão apresentar diferentes tomadas de posição, (c) que estão ancoradas em suas diferentes pertenças e realidades socioculturais. 
Doise (1992) propõe o estudo das representações sociais enfatizando a variabilidade interindividual do campo representacional, posto que os diversos pertencimentos e interações sociais geram diferentes posicionamentos frente aos objetos de representação. De acordo com Almeida (2009, p. 719), "é evidente o objetivo dessa abordagem em conectar o individual ao coletivo, de buscar a articulação de explicações de ordem individual com explicações de ordem societal", tarefa que implica considerar também o nível ideológico na produção da vida social. Como instrumentos da hegemonia, que justificam e orientam o sistema social, as ideologias atuam por meio de representações sociais, que produzidas e compartilhadas socialmente, constituem a própria realidade dos indivíduos e grupos (Doise, 1982).

Pesquisas desenvolvidas a partir da abordagem societal têm demonstrado suas contribuições à análise de fenômenos representacionais, tais como os estudos sobre as representações sociais de alimentação entre crianças de diferentes culturas (romenas, canadenses e canadenses de origem romena), evidenciando os efeitos dos contextos ideológico-culturais na variabilidade do conteúdo de representações sociais (Grabovschi, 2011). Outro exemplo são os estudos sobre as representações sociais dos direitos das crianças entre italianos e jordanianos, demonstrando que os valores sociais característicos de cada nacionalidade e cultura modulam diferentes representações acerca do objeto social (Monacelli, Molinari, \& Emiliani, 2007).

Sobre o quadro teórico-metodológico em que se fundamenta essa abordagem, também conhecida como paradigma das três fases, este se baseia no desenvolvimento do estudo das representações por meio de três fases (Doise, 1992; Doise, Clémence \& Lorenzi-Cioldi, 1992): composição do campo representacional ou do universo semântico associado aos objetos de representação, identificação dos princípios organizadores das diferenças individuais (variabilidade do campo representacional) e análise dos processos de ancoragem dos princípios organizadores das representações sociais.

Entendendo, portanto, a consensualidade das representações sociais como compartilhamento de tomadas de posição dos indivíduos, caracterizadas por ancoragens em realidades sociopsicológicas diversificadas, porém compartilhadas no interior dos grupos sociais, segundo Doise (1982), há que se considerar as contradições, similaridades e pluralidades de significados e suas funções, formulados a partir da relação elementar entre representações e pertenças sociais (Clémence et al., 1994; Deschamps \& Moliner, 2009). Essa proposição orienta a análise do campo representacional em questão a partir dos processos de ancoragem psicológica e social, que se referem, respectivamente, ao posicionamento interindividual frente ao conteúdo das representações sociais e às experiências compartilhadas pelos sujeitos em dado contexto sociocultural de inserção (Doise, 1992).

Tendo em vista as considerações apresentadas, o estudo teve como proposição principal investigar as representações sociais de mulher cigana, entre brasileiros e italianos não ciganos, a partir dos objetivos específicos de: (a) conhecer o campo semântico associado ao objeto de representação Mulher Cigana; (b) investigar os princípios organizadores das tomadas de posição individuais em relação ao conteúdo compartilhado das representações sociais abordadas; e (c) analisar os processos de ancoragem psicológica e social das representações sociais em questão.

\section{Método}

\section{Participantes e Procedimentos de Coleta dos Dados}

Participaram do estudo 643 sujeitos não ciganos (324 italianos e 319 brasileiros). Na Itália, a coleta dos dados foi realizada por meio da aplicação de questionários a estudantes da Universidade de Bolonha e de Chieti-Pescara. No Brasil, participaram da pesquisa universitários da Universidade Federal do Espírito Santo. Com duração média de 40 minutos, a aplicação do instrumento ocorreu durante as aulas dos cursos de graduação.

No total, a amostra é composta por 478 mulheres (256 italianas e 222 brasileiras) e por 147 homens (50 italianos e 97 brasileiros), sendo que 18 sujeitos italianos não declararam o próprio sexo. A distribuição do sexo em função das duas nacionalidades indica ligeira prevalência significativa $\left(\chi^{2}(1)\right.$ $=17.2, p<0,001)$ de mulheres na Itália $(53,6 \%$ ITA vs. 34\% BRA) e de homens no Brasil (46,4\% ITA vs. $66 \%$ BRA). A idade média, por sua vez, é de 22,81 anos $(S D=5,73)$, não tendo sido encontradas diferenças relevantes entre italianos e brasileiros.

No que se refere ao pertencimento étnico dos respondentes, segundo categoria autodeclarada, o grupo de italianos é composto quase exclusivamente por brancos $(98 \%)$, além de três sujeitos pardos $(1 \%)$, dois negros $(0,7 \%)$ e um asiático $(0,3 \%)$. O grupo de brasileiros é mais heterogêneo, posto que é constituído quase em igual medida por brancos $(42,9 \%)$ e pardos $(38,1 \%)$, seguidos de negros $(16 \%)$, asiáticos $(1,6 \%)$ e indígenas $(1,3 \%)$.

Em relação à religião, a maior parte dos italianos se reconhece como católicos $(59,2 \%)$ ou, em termos mais genéricos, cristãos $(17,6 \%)$, seguidos de um grupo de ateus $(15,1 \%)$ ou agnósticos $(3,5 \%)$ e de ortodoxos $(1,1 \%)$, budistas $(1,1 \%)$, hebreus $(0,7 \%)$, muçulmanos $(0,7 \%)$, cristãos evangélicos $(0,7 \%)$ ou adeptos da scientology $(0,4 \%)$. Entre os brasileiros, predominam os católicos $(44,7 \%)$, somados a mais de um quarto de cristãos evangélicos $(26,3 \%)$, seguidos pelos ateus $(21,1 \%)$, pelos membros do espiritismo $(5,6 \%)$ e das religiões afro-brasileiras Umbanda e Candomblé $(1,4 \%)$, além daqueles que se declaram católicos e espíritas $(0,7 \%)$ e evangélicos e espíritas $(0,3 \%)$.

No que concerne à orientação política, por sua vez, medida a partir de uma escala de 7 pontos $(1=$ esquerda e 7 = direita), a amostra se posiciona majoritariamente na categoria centro-esquerda $(M=3,63, S D=1,4)$. Os sujeitos italianos localizam-se ligeiramente mais à esquerda do que os brasileiros $\left(\mathrm{M}_{\mathrm{Ita}}=3,50, \mathrm{M}_{\mathrm{Bra}}=3,74, F(1-536)=3,81, p\right.$ $=0,05$ ).

Finalmente, sobre a seleção dos territórios e contextos nacionais para desenvolvimento do estudo, parece ser importante informar que a presente proposição baseou-se na existência de uma rede de pesquisadores brasileiros e italianos sobre a questão cigana, estratégia de valorização 
da inserção territorial dos pesquisadores que tem sido amplamente explorada nos estudos transculturais (Shiraev \& Levy, 2015).

\section{Instrumentos e Tratamentos dos Dados}

Conforme método de investigação proposto por Doise et al. (1992), a coleta dos dados foi procedida por meio de um questionário, com questões abertas e fechadas, contendo as seguintes seções: 1. Dados sócio-demográficos referentes à idade, sexo, religião, pertencimento étnico, orientação política e nacionalidade; e 2. Associação livre para o termo indutor mulher cigana (conteúdo produzido a partir da questão: "O que você pensa, sente ou imagina quando eu falo 'mulher cigana'? Escreva 05 palavras ou frases que lhe vêm em mente").

Os dados foram analisados com o auxílio do software francês SPAD-T para análise de dados textuais (Doise, et al., 1992; Lebart, Morineau, Becue, \& Haeusler, 1994), por meio da análise de correspondência lexical e de clusterização realizadas através do procedimento ASPAR, bem como da identificação das palavras características dos clusters identificados (tratamento realizado por meio do procedimento MOCAR). No que se refere especificamente ao corpus de dados constituído pelas associações livres (questão do tipo aberta), na fase inicial da análise, procedeu-se a uma categorização semântica, a fim de se obter um número reduzido de categorias, agrupando respostas semelhantes, padronizando palavras no singular/plural e reduzindo frases à unidade de codificação. O procedimento foi conduzido por dois juízes independentes e devidamente treinados e, em caso de discordância ou ambiguidade, um terceiro juiz procedeu à análise do material.

\section{Resultados}

\section{Análise do Conteúdo Compartilhado das Representações Sociais de Mulher Cigana}

Associadas ao termo indutor mulher cigana, foram produzidas 3.004 evocações, com média de 4,7 associações por participante, sendo que o número de elementos distintos foi de 337 , o que corresponde a $11,2 \%$ do total de respostas. A Tabela 1 mostra as frequências dos termos evocados, com os elementos mais frequentes (foram considerados termos com frequência maior ou igual a 8), que puderam ser reduzidos a 10 áreas temáticas.

O método da associação livre, usado frequentemente nas pesquisas sobre representações sociais, é indicado como uma das estratégias privilegiadas nesse campo de estudo (Bonomo, Souza, Melotti \& Palmonari, 2013; Doise et al., 1992). Esse método consiste em propor uma palavra-estímulo e pedir aos participantes que associem livremente cada ideia ou sentimento que vem à cabeça ao objeto social. Por meio desse recurso, acessa-se o conteúdo das representações sociais.

As categorias elaboradas, descritas a seguir, fornecem um panorama dos elementos que constituem o conteúdo compartilhado das representações sociais de mulher cigana, contribuindo para a exploração inicial dos significados que constituem o campo representacional:

1). Os elementos Lê mão, Lê o futuro, Cartomante, Misticismo, Feiticeira, Mistério, Quiromante e Vidente referem-se a uma representação romantizada, mágicoreligiosa e repleta de mistério: a mulher cigana capaz de prever o futuro;

2) A partir dos termos Usa os filhos, Rouba crianças, Mãe malvada e Má, estabelece-se um campo semântico em que a mulher cigana aparece associada à imagem de uma pessoa ruim e aproveitadora de crianças;

3) Os significados Suja, Incomoda, Mal cuidada, Grotesca, Ignorante, Mal-educada, Feia, Preguiçosa e Fede, por sua vez, referem-se a uma imagem negativa da cigana, caracterizada por meio de aspectos físicos desagradáveis e da ausência de autocuidado;

4) O quarto agrupamento, por meio dos elementos Muitos filhos, Mãe, Rodeada de crianças, Dona de casa, Casa jovem, Cuida da família, Grávida, Mãe jovem, Crianças, Filhos e Chefe de família, orienta a construção de uma representação tradicional da mulher cigana: a rainha do lar, cheia de filhos e dedicada aos cuidados da família e da casa;

5) Esse conjunto de significados compreende categorias que fazem referência às condições de marginalidade, exploração e pobreza vividas pelas ciganas: Esmola, Submissa, Pobre, Marginalizada, Desfavorecida, Submissa aos homens, Triste, Coagida, Explorada, Sofrida, Necessitada e Sem instrução;

6) Nesse campo semântico, estão presentes significados que retratam as ciganas a partir da sensualidade e sedução (Sensual, Sedutora e Vaidosa), podendo assumir um cunho negativo representado na imagem da mulher Prostituta;

7) Termos como Rouba, Não trabalha, Mentirosa, Esperta, Ladra, Tenho medo, Dinheiro, Enganadora e Aproveitadora fazem referência a características negativas atribuídas à cigana, a partir da ideia de que esta seria ladra e trapaceira;

8) No oitavo campo semântico, constituído pelas palavras Danças, Nômade, Estrada, Grupo, Cultura, Tradições, Sem casa, Diferente e Estranha, vem evocada a especificidade cultural, com tradições e modo de vida diferentes e, por vezes, estranhos ao sujeito da representação;

9) Elementos como Bonita, Forte, Livre, Batalhadora, Trabalha, Alegria, Boa e Mulher constroem uma imagem positiva da mulher cigana: uma mulher bonita, emancipada (talvez porque trabalha), livre e cheia de alegria;

10) Finalmente, na última categoria temática, podem ser encontradas palavras como Saias longas, Vestidos coloridos, Cabelos longos, Vestidos diferentes, Vestidos longos, Joias, Ouro, entre outros elementos relativos à dimensão icônica da representação social, tal como elaborada pelos respondentes.

Processos de Ancoragem das Representações Sociais de Mulher Cigana 
Tabela 1. Conteúdo Compartilhado das Representações Sociais de Mulher Cigana

\begin{tabular}{|c|c|c|c|c|c|c|c|c|}
\hline & Termos & $\mathrm{f}$ & & Termos & $\mathrm{f}$ & & Termos & f \\
\hline 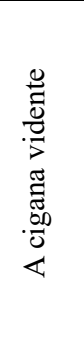 & $\begin{array}{l}\text { Lê mão } \\
\text { Lê o futuro } \\
\text { Cartomante } \\
\text { Misticismo } \\
\text { Feiticeira } \\
\text { Mistério } \\
\text { Quiromante } \\
\text { Vidente }\end{array}$ & $\begin{array}{l}143 \\
25 \\
24 \\
21 \\
17 \\
14 \\
11 \\
09\end{array}$ & 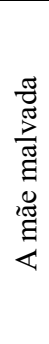 & $\begin{array}{l}\text { Usa os filhos } \\
\text { Rouba crianças } \\
\text { Mãe malvada } \\
\text { Má }\end{array}$ & $\begin{array}{l}24 \\
16 \\
15 \\
10\end{array}$ & 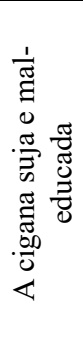 & $\begin{array}{l}\text { Suja } \\
\text { Incomodam } \\
\text { Mal cuidada } \\
\text { Grotesca } \\
\text { Ignorante } \\
\text { Mal-educada } \\
\text { Feia } \\
\text { Preguiçosa } \\
\text { Fede }\end{array}$ & $\begin{array}{l}111 \\
26 \\
26 \\
15 \\
10 \\
11 \\
08 \\
08 \\
08\end{array}$ \\
\hline 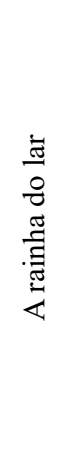 & $\begin{array}{l}\text { Muitos filhos } \\
\text { Mãe } \\
\text { Rodeada de crianças } \\
\text { Dona de casa } \\
\text { Casa jovem } \\
\text { Cuida da família } \\
\text { Grávida } \\
\text { Mãe jovem } \\
\text { Crianças } \\
\text { Filhos } \\
\text { Chefe de família }\end{array}$ & $\begin{array}{l}97 \\
59 \\
43 \\
30 \\
22 \\
21 \\
16 \\
15 \\
14 \\
10 \\
08\end{array}$ & 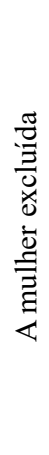 & $\begin{array}{l}\text { Esmola } \\
\text { Submissa } \\
\text { Pobre } \\
\text { Marginalizada } \\
\text { Desfavorecida } \\
\text { Submissa aos homens } \\
\text { Triste } \\
\text { Coagida } \\
\text { Explorada } \\
\text { Sofrida } \\
\text { Necessitada } \\
\text { Sem instrução }\end{array}$ & $\begin{array}{l}121 \\
75 \\
54 \\
31 \\
18 \\
16 \\
13 \\
11 \\
11 \\
09 \\
09 \\
08\end{array}$ & 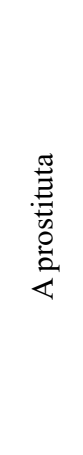 & $\begin{array}{l}\text { Sensualidade } \\
\text { Vaidosa } \\
\text { Sedutora } \\
\text { Prostituta }\end{array}$ & $\begin{array}{l}15 \\
15 \\
14 \\
08\end{array}$ \\
\hline 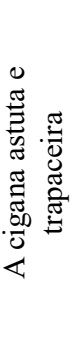 & $\begin{array}{l}\text { Rouba } \\
\text { Não trabalha } \\
\text { Mentirosa } \\
\text { Esperta } \\
\text { Ladra } \\
\text { Tenho medo } \\
\text { Dinheiro } \\
\text { Enganadora } \\
\text { Aproveitadora }\end{array}$ & $\begin{array}{l}57 \\
31 \\
30 \\
29 \\
25 \\
21 \\
15 \\
15 \\
11\end{array}$ & 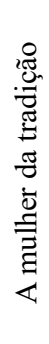 & $\begin{array}{l}\text { Danças } \\
\text { Nômade } \\
\text { Estrada } \\
\text { Grupo } \\
\text { Cultura } \\
\text { Tradições } \\
\text { Sem casa } \\
\text { Diferente } \\
\text { Estranha }\end{array}$ & $\begin{array}{l}75 \\
45 \\
32 \\
29 \\
20 \\
15 \\
13 \\
12 \\
08\end{array}$ & 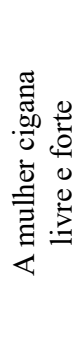 & $\begin{array}{l}\text { Bonita } \\
\text { Forte } \\
\text { Livre } \\
\text { Batalhadora } \\
\text { Trabalha } \\
\text { Alegria } \\
\text { Boa } \\
\text { Mulher }\end{array}$ & $\begin{array}{l}25 \\
17 \\
17 \\
15 \\
14 \\
13 \\
11 \\
11\end{array}$ \\
\hline 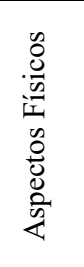 & $\begin{array}{l}\text { Saias longas } \\
\text { Vestidos coloridos } \\
\text { Cabelos longos } \\
\text { Vestidos diferentes } \\
\text { Vestidos longos } \\
\text { Joias } \\
\text { Ouro }\end{array}$ & $\begin{array}{l}86 \\
71 \\
65 \\
52 \\
45 \\
36 \\
31\end{array}$ & 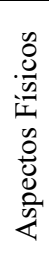 & $\begin{array}{l}\text { Vestidos } \\
\text { Colorida } \\
\text { Dentes de ouro } \\
\text { Morena } \\
\text { Saias } \\
\text { Bijuterias } \\
\text { Brincos }\end{array}$ & $\begin{array}{l}30 \\
22 \\
21 \\
21 \\
20 \\
18 \\
18\end{array}$ & 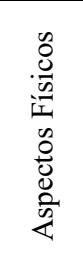 & $\begin{array}{l}\text { Tranças } \\
\text { Vestidos maltrapilhos } \\
\text { Anéis/colares/pulseiras } \\
\text { Pés descalços } \\
\text { Saias coloridas } \\
\text { Lenços }\end{array}$ & $\begin{array}{l}15 \\
15 \\
14 \\
12 \\
11 \\
09\end{array}$ \\
\hline
\end{tabular}

Nota. Lista de 94 palavras com frequência acima de 8.

Seguindo a orientação teórico-metodológica do paradigma das três fases (Doise et al., 1992), procedeu-se à análise do campo semântico do objeto de representação social da seguinte forma: ancoragem psicológica, evidenciada através da análise de correspondência lexical e da formação de clusters compostos por sujeitos segundo o conjunto de elementos das representações sociais do objeto; e ancoragem social, investigada por meio da projeção, nos fatores analisados, das variáveis suplementares.

\section{Ancoragem Psicológica}

Com a finalidade de evidenciar as diferenças individuais em relação ao objeto de representação, procedeu-se à análise de correspondência lexical (Lebart et al., 1994) utilizando o procedimento ASPAR do SPAD-T. Essa análise permite identificar os princípios sobre os quais se organizam as tomadas individuais dos sujeitos da representação (os polos opostos dos eixos). Além disso, por meio da análise de cluster, é possível identificar diferentes grupos de sujeitos, homogêneos no interior para as respostas fornecidas, que são representativas das tomadas de posição individuais em relação ao objeto de representação.

A Figura 1 mostra o plano fatorial originado a partir do cruzamento entre o primeiro e o segundo eixos, que explicam $4,84 \%$ da inércia total $(\tau=23,17)$.

No primeiro eixo $(2,54 \%$ de inércia), sobre o polo negativo, encontra-se uma imagem positiva, porém romantizada da cigana, vista como uma mulher em torno da qual se cria uma atmosfera de Misticismo (c.a. $=3,20$ ) e Mistério (c.a. $=2,00)$, talvez graças ao fato de que, geralmente, Trabalha (c.a. $=1,60)$ lendo a mão (Lê mão c.a. $=4,30$ ) das pessoas. Uma mulher que se diferencia com seus Vestidos (c.a. $=2,70)$ Coloridos (c.a. $=2,80)$ e Joias (c.a. $=$ $2,50$ ) douradas (Ouro, c.a. $=1,40)$ e que manifesta sua Alegria $($ c.a. $=1,20)$ e liberdade (Livre, c.a. $=1,20)$ por meio das Danças (c.a. = 6,30). Em função disso, por vezes, aparece como Vaidosa (c.a. =2,80), mas também Bonita (c.a. =3,50), Boa $($ c.a. $=1,10)$ e cheia de Sensualidade $($ c.a. $=1,70)$. 


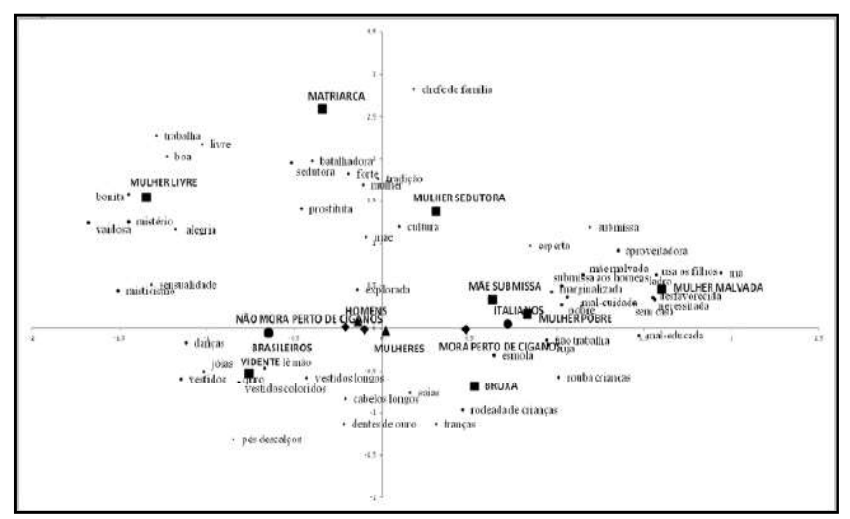

Figura 1. Representações sociais de mulher cigana: análise de correspondência lexical

Nota. Análise do cruzamento dos eixos fatoriais 1 e 2, que explicam 8,84\% da inércia total. No procedimento ASPAR, é normal que o percentual de inércia tenha valores baixos, na medida em que se distribui sobre um total de fatores, sendo possível extrair que corresponde a $\mathrm{k}-1(\mathrm{k}=$ número de categorias analisadas. Nesse caso, $\mathrm{k}=94)$. Para determinar o nível de aceitação das categorias, utiliza-se a regra c.a. $\geq 100 / \mathrm{n}$ de categorias (c. a. $\geq 1,06$ ), enquanto que, para determinar o nível de aceitação das variáveis suplementares, utiliza-se o critério $\mathrm{V}$-test $(\mathrm{V}) \geq|2|$.

No polo oposto (polo positivo), surge uma imagem que agrupa diversos significados negativos: a cigana é descrita como Suja (c.a. =6,70), Mal cuidada (c.a. =2,00) e Maleducada (c.a. $=1,60)$, uma Ladra (c.a. $=3,70)$, Aproveitadora $($ c.a. $=1,30)$, Esperta (c.a. $=1,40)$ e Má $($ c.a. $=2,50)$, que Rouba crianças (c.a. =1,10); uma Mãe má $($ c.a. $=1,30)$ que pede Esmola (c.a. $=3,30)$ e Usa os filhos (c.a. $=4,00)$, mas também uma mulher Marginalizada (c.a. $=1,90)$, Desfavorecida (c.a. $=2,90)$ e Necessitada (c.a. $=1,40)$; por isso, Pobre (c.a. $=3,90)$, Sem casa $($ c.a. $=1,80)$ e Sem trabalho (c.a. $=1,80)$, geralmente Submissa aos homens do próprio grupo (c.a. $=1,10)$. Tendo em vista seu conteúdo característico, o primeiro eixo foi definido por meio da polaridade A cigana misteriosa vs. A cigana marginalizada.

No segundo eixo $(2,30 \%$ de inércia), por sua vez, sobre o polo negativo, encontra-se a descrição do aspecto físico da cigana: uma mulher com Dentes de ouro (c.a. $=2,00)$, com Cabelos longos (c.a. $=3,40)$ e com Tranças (c.a. $=$ $1,40)$, que veste Saias (c.a. $=3,70$ ) e Vestidos longos (c.a. $=1,10)$ e Coloridos (c.a. $=2,30)$, que caminha com os Pés descalços (c.a. = 1,5); geralmente está Rodeada de crianças $($ c.a. $=3,0)$, enquanto Lê a mão $($ c.a. $=2,30)$ das pessoas nas ruas e praças da cidade.

Sobre o polo oposto (polo positivo), a cigana aparece retratada a partir de diferentes significados associados ao feminino: uma Mulher (c.a. = 2,40) Bonita (c.a. = 4,60) e Livre (c.a. $=6,00)$, que Trabalha (c.a. $=5,30)$, é Batalhadora $($ c.a. $=4,40)$, Boa (c.a. $=3,40)$ e alegre (Alegria - c.a. $=$ $1,30)$; uma Mãe (c.a. = 5,00) Forte (c.a. = 4,20), a quem é atribuído o papel de Chefe de família (c.a. $=4,70$ ), que encontra a sua realização por meio do respeito às Tradições $($ c.a. $=3,50)$ seguindo sua Cultura $($ c.a. $=2,10)$, mesmo que isso possa torná-la Submissa (c.a. $=1,20)$ e Explorada (c.a. $=1,10)$ no interior das relações de seu próprio grupo; mas também uma pessoa Esperta (c.a. $=2,00)$ e Vaidosa (c.a. $=1,70)$, que encontra a sua força na capacidade de criar um clima de Mistério (c.a. $=1,60$ ) graças ao seu poder de sedução (Sedutora - c.a. $=4,00)$, podendo ainda ser associada à imagem de Prostituta $(\mathrm{c} . \mathrm{a}=1,20)$. A polaridade concernente ao segundo eixo foi denominada de A cigana vidente $v s$. As diversas faces da mulher, por se referirem, respectivamente, à dimensão icônica das representações sociais de cigana e às diferentes imagens da mulher, associadas ao objeto social em análise.

Por meio da análise de classificação, implementada no procedimento ASPAR do SPAD-T, foi possível identificar oito clusters de sujeitos que associaram ao termo indutor mulher cigana diferentes agrupamentos de categorias e que exprimem, portanto, oito diferentes representações sociais (Bonomo et al., 2013). Todos os clusters se posicionam significativamente sobre os planos fatoriais apresentados na Figura 1. Na Tabela 2, é descrita a composição dos clusters com os elementos mais característicos de cada agrupamento.

O Cluster 1 agrupa 80 participantes (16 homens e 59 mulheres - 5 não informaram o sexo; 57 italianos e 23 brasileiros), que evocaram com maior frequência elementos relativos à condição de pobreza e marginalização vivenciada pelas mulheres ciganas: Pobre, Não trabalha, Diferente, Sem casa, Muitos filhos, Cultura, Explorada, Marginalizada, Mal cuidada e Nômade. Por esse motivo, essa representação foi denominada Mulher pobre.

O Cluster 2 é constituído por 77 sujeitos (13 homens e 64 mulheres; 63 italianos e 14 brasileiros), que associaram às ciganas elementos como Desfavorecida, Submissa aos homens, Mãe jovem, Submissa, Marginalizada, Coagida, Cuida da família, Sem instrução, Dona de casa e Mãe. Esses sujeitos parecem evocar a imagem da mulher jovem, submissa aos homens do próprio grupo, constrangida ao papel da mãe e dona de casa. A representação referente a esse cluster foi chamada de Mãe submissa.

O Cluster 3, menos numeroso, é formado por 29 sujeitos ( 5 homens e 24 mulheres; 14 italianos e 15 brasileiros), que evocaram os seguintes termos: Mãe, Trabalha, Tradições, Chefe de família, Forte, Cultura, Boa, Mulher e Submissa. Esse agrupamento parece fazer referência àquela mulher que, por tradição e cultura, volta-se ao domínio da família e do lar, diferenciando-se do Cluster 2 pelo papel de liderança no grupo familiar. Por isso, foi chamado de Matriarca.

Também o Cluster 4 constitui-se como agrupamento não numeroso (30 sujeitos, sendo 8 homens e 21 mulheres - um sujeito não forneceu o dado; 17 italianos e 13 brasileiros). Os elementos que o caracterizam são: Batalhadora, Esperta, Sofrida, Forte, Sedutora, Cartomante, Mulher, Tenho medo, Ladra e Mãe malvada. A representação referente a esse cluster foi chamada de Mulher sedutora.

O Cluster 5 agrupa 44 participantes ( 7 homens e 34 mulheres - 3 não informaram o sexo; 39 italianos e 5 brasileiros) que apresentam uma representação negativa da cigana. Quem pertence a esse grupo, chamado de Mulher malvada, associa elementos tais como: Usa os filhos, Aproveitadora, Mal-educada, Má, Suja, Mentirosa, Incomoda, Preguiçosa, Grotesca e Grávida.

O Cluster 6 reúne 47 participantes (20 homens e 26 mulheres - um respondente não forneceu a informação; 9 italianos e 38 brasileiros), que evocaram mais frequentemente elementos, tais como: Bonita, Livre, Mistério, Vaidosa, Prostituta, Alegria, Boa, Misticismo, Sensualidade e 
Feiticeira. Em função do conteúdo característico, esse cluster foi denominado de Mulher livre.

O sétimo agrupamento (Cluster 7) é formado por 126 sujeitos (26 homens e 95 mulheres - 5 sem resposta; 99 italianos e 27 brasileiros), que constroem a representação social de mulher cigana a partir dos elementos Rodeada de crianças, Saias longas, Tranças, Esmola, Suja, Cabelos longos, Rouba crianças, Fede, Vestidos maltrapilhos e Lenços. A imagem produzida a partir desse cluster foi chamada de Bruxa, porque parece evocar a clássica bruxa que rouba as crianças, conforme figura retratada nas histórias infantis.

Por fim, o Cluster 8, o mais numeroso, foi elaborado a partir do agrupamento de 210 respondentes ( 52 homens e 155 mulheres - 3 sem resposta; 26 italianos e 184 brasileiros). Os termos que o caracterizam são: Lê mão, Danças, Vestidos coloridos, Joias, Vestidos, Lê o futuro, Bijuterias, Vestidos longos, Anéis/colares/pulseiras e Ouro. Esses significados se referem à imagem estereotipada da cigana, que, adornada com os vestidos e joias típicos, pode prever o futuro. Em função dessa imagem, esse cluster foi chamado de Vidente.

A análise dos resíduos padronizados e corrigidos, obtidos a partir da aplicação do teste do $\chi^{2}\left(\chi^{2}(7)=14,69, p=0,04\right)$ ao cruzamento das variáveis sexo $v s$. cluster, evidencia que a representação de Mulher livre ocorre mais frequentemente entre os homens (13,6\% do sexo masculino vs. 5,4\% do sexo feminino; adj. res. masculino $=3,30$, adj. res feminino $\left._{\text {. }}=-3,30\right)$. A mesma análise aplicada à tabulação cruzada nacionalidade vs. cluster $\left(\chi^{2}(7)=250,36 ; p<0,001\right)$, evidenciou que os italianos recorrem mais frequentemente às representações de Mulher pobre (17,6\% ITA vs. 7,2\% BRA; adj. res. ${ }_{\text {Ita }}=4,00$, adj. res. . $\left._{\text {Bra }}=-4,00\right)$, Mãe submissa (19,4\% ITA vs. 4,4\% BRA; adj. res. ${ }_{\text {Ita }}=5,90$, adj. res. $\left.{ }_{\text {Bra }}=-5,90\right)$, Mulher malvada $(12, \%$ ITA vs. 1,6\% BRA; adj. res. . $_{\text {Ita }}=5,30$, adj.res. $\left.._{\text {Bra }}=-5,30\right) \mathrm{e}$ Bruxa (30,6\% ITA vs. 8,5\% BRA; adj.res. $._{\text {Ita }}=7,10$, adj.res. $=-7,10)$, enquanto os brasileiros à de Mulher livre $(2,8 \%$ ITA vs. $11,9 \%$ BRA; adj. res. Ita $_{\text {Ita }}=-4,40$, adj. res. . $\left._{\text {Bra }}=4,40\right)$ e Vidente $\left(8,0 \%\right.$ ITA vs. 57,7\% BRA; adj. res. Ita $_{\text {. }}=-13,40$, adj. res. . $\left._{\text {Bra }}=13,40\right)$.

A partir da projeção dos diferentes grupos no plano fatorial, observa-se que se localizam no polo A cigana misteriosa do primeiro eixo os Clusters 3 Matriarca $(V=-3,2$, coord $1=-0,34), 6$ Mulher livre $(V=-18,5$, coord $1=-1,35)$ e 8 Vidente $(V=-29,2$, coord $1=-0,76)$, e, no polo A, cigana marginalizada os Clusters 1 Mulher pobre $(V=15,4$, coord 1 $=0,83), 2$ Mãe submissa $(V=10,6$, coord1 $=0,63), 4$ Mulher sedutora $(V=3,2$, coord $1=0,31), 5$ Mulher malvada $(V=$ $-20,8$, coord $1=1,60)$ e 7 Bruxa $(V=13,6$, coord $1=0,53)$.

No segundo eixo, associada à dimensão icônica da cigana (A cigana vidente), estão os Clusters 7 Bruxa $(V=-17,6$, coord2 $=-0,68)$ e 8 Vidente $(V=-19,9$, coord2 $=-0,52)$, e, no polo oposto, os agrupamentos 1 Mulher pobre $(V=3,2$, coord2 $=0,17), 2$ Mãe submissa $(V=5,6$, coord2 $=0,33), 3$ Matriarca $(V=24,4$, coord2 $=2,59), 4$ Mulher sedutora $(V$ $=14,1$, coord $2=1,37), 5$ Mulher malvada $(V=5,9$, coord2 $=0,46)$ e 6 Mulher livre $(V=21,1$, coord $2=1,54)$.

Tabela 2. Representações Sociais de Mulher Cigana-Clusters de Sujeitos em Função do Conteúdo Característico

\begin{tabular}{|c|c|c|c|c|c|c|c|}
\hline \multicolumn{2}{|c|}{$\begin{array}{c}\text { Cluster } 1 \\
\text { Mulher pobre } \\
\text { (80 sujeitos) }\end{array}$} & \multicolumn{2}{|l|}{$\begin{array}{c}\text { Cluster } 2 \\
\text { Mãe submissa } \\
\text { (77 sujeitos) }\end{array}$} & \multicolumn{2}{|l|}{$\begin{array}{c}\text { Cluster } 3 \\
\text { Matriarca } \\
\text { (29 sujeitos) }\end{array}$} & \multicolumn{2}{|c|}{$\begin{array}{c}\text { Cluster } 4 \\
\text { Mulher sedutora } \\
\text { (30 sujeitos) }\end{array}$} \\
\hline Elementos & $\mathrm{V}$ & Elementos & $\mathrm{V}$ & Elementos & $\mathrm{V}$ & Elementos & $\mathrm{V}$ \\
\hline Pobre & 10,67 & Desfavorecida & 7,65 & Mãe & 6,18 & Batalhadora & 7,75 \\
\hline Não trabalha & 5,67 & Submissa aos homens & 7,06 & Trabalha & 5,80 & Esperta & 6,17 \\
\hline Diferente & 5,44 & Mãe jovem & 6,18 & Tradições & 5,67 & Sofrida & 5,72 \\
\hline Sem casa & 5,19 & Submissa & 5,47 & Chefe de família & 5,39 & Forte & 3,33 \\
\hline Muitos filhos & 4,76 & Marginalizada & 4,50 & Forte & 4,22 & Sedutora & 2,89 \\
\hline Cultura & 4,01 & Coagida & 4,07 & Cultura & 2,65 & Cartomante & 2,83 \\
\hline Explorada & 3,81 & Cuida da família & 3,73 & Boa & 2,56 & Mulher & 2,38 \\
\hline Marginalizada & 3,69 & Sem instrução & 3,32 & Mulher & 2,56 & Tenho medo & 2,36 \\
\hline Mal cuidada & 3,32 & Dona de casa & 3,32 & Submissa & 2,24 & Ladra & 2,12 \\
\hline Nômade & 2,96 & Mãe & 3,28 & & & Mãe malvada & 2,03 \\
\hline \multicolumn{2}{|c|}{$\begin{array}{c}\text { Cluster } 5 \\
\text { Mulher malvada } \\
\text { (44 sujeitos) }\end{array}$} & \multicolumn{2}{|l|}{$\begin{array}{c}\text { Cluster } 6 \\
\text { Mulher livre } \\
\text { (47 sujeitos) }\end{array}$} & \multicolumn{2}{|l|}{$\begin{array}{c}\text { Cluster } 7 \\
\text { Bruxa } \\
\text { (126 sujeitos) }\end{array}$} & \multicolumn{2}{|c|}{$\begin{array}{c}\text { Cluster } 8 \\
\text { Vidente } \\
\text { (210 sujeitos) }\end{array}$} \\
\hline Elementos & $\mathrm{V}$ & Elementos & $\mathrm{V}$ & Elementos & $\mathrm{V}$ & Elementos & $\mathrm{V}$ \\
\hline Usa os filhos & 8,97 & Bonita & 8,16 & Rodeada de crianças & 9,46 & Lê mão & 10,77 \\
\hline Aproveitadora & 6,08 & Livre & 8,11 & Saias longas & 8,74 & Danças & 8,45 \\
\hline Mal-educada & 5,43 & Mistério & 6,51 & Tranças & 5,81 & Vestidos coloridos & 7,51 \\
\hline Má & 4,97 & Vaidosa & 5,20 & Esmola & 5,76 & Joias & 7,21 \\
\hline Suja & 3,98 & Prostituta & 4,57 & Suja & 5,37 & Vestidos & 6,38 \\
\hline Mentirosa & 3,88 & Alegria & 4,32 & Cabelos longos & 5,30 & Lê futuro & 4,68 \\
\hline Incomoda & 3,16 & Boa & 3,98 & Rouba crianças & 3,91 & Bijuterias & 4,36 \\
\hline Preguiçosa & 2,30 & Misticismo & 3,94 & Fede & 3,70 & Vestidos longos & 4,27 \\
\hline Grotesca & 2,27 & Sensualidade & 3,44 & Vestidos maltrapilhos & 3,61 & Anéis/colares/ & 4,12 \\
\hline Grávida & 2,17 & Feiticeira & 3,22 & Lenços & 3,35 & pulseiras Ouro & 4,09 \\
\hline
\end{tabular}

Nota. Listagem dos termos mais frequentes segundo critério V-test $(V) \geq|2|$ 


\section{Ancoragem Social}

Para evidenciar como as diferentes pertenças dos participantes modulam as representações sociais de mulher cigana, foram analisadas as posições dos sujeitos (os grupos se projetam significativamente sobre o plano fatorial se $\mathrm{V}$-test $(V) \geq|2,0|)$ sobre os eixos fatoriais a partir das variáveis sexo, nacionalidade e proximidade que os sujeitos declaram ter com a população cigana (avaliada por meio da pergunta "Existem ciganos que vivem perto de você na sua cidade?").

No primeiro fator, projetam-se significativamente sobre o polo A cigana misteriosa os homens $(V=-3,7$, coord1 $=$ $-0,14)$, quem não vive próximo aos ciganos (227 sujeitos - $V=-7,6$, coord $1=-0,21$ ) ou não sabe da existência de acampamentos ciganos próximos à sua residência (264 sujeitos $-V=-4,3$, coord $1=-0,10)$ e os brasileiros $(V=$ $-34,6$, coord $1=-0,65)$. No polo A cigana marginalizada desse mesmo fator, encontram-se as mulheres $(V=1,9$, coord $1=$ $0,02)$, quem vive próximo aos ciganos (145 indivíduos, $V=$ $12,8$, coord $1=0,48)$ e os italianos $(V=34,6$, coord $1=0,72)$.

Associados ao polo negativo (A cigana vidente), no segundo fator, projetam-se as mulheres $(V=-2,0$, coord $2=$ $-0,02)$ e os brasileiros $(V=-2,5$, coord $2=-0,05)$, enquanto, no polo oposto, As diversas faces da mulher, encontram-se os homens $(V=2,3$, coord $2=0,08)$ e os italianos $(V=2,5$, $\operatorname{coord} 2=0,05)$.

\section{Discussão}

Orientados pela tarefa de identificar (a) o campo semântico compartilhado associado ao objeto de representação mulher cigana, (b) os princípios organizadores das diferenças individuais, bem como (c) os processos de ancoragem do conteúdo representacional (Doise, et al., 1992), discutemse os resultados encontrados a partir da função das representações sociais, segundo sua natureza e dinâmica.

Evidenciando as modulações interindividuais do campo representacional, em consonância com o processo de ancoragem psicológica (Doise, 1982, 1992, 2011), identificou-se a elaboração de oito grupos de sujeitos orientados por diferentes representações sociais de mulher cigana, a partir das dimensões: maternidade e cuidado com o grupo e família (Clusters 2 Mãe submissa e 3 Matriarca), imagens do feminino (Clusters 4 Mulher sedutora, 5 Mulher malvada e 6 Mulher livre), exclusão social (Cluster 1 Mulher pobre) e universo mágico-religioso (Clusters 7 Bruxa e 8 Vidente).

As tematizações ou as unidades semânticas de base (Marková, 2000), constitutivas das representações sociais de mulher cigana identificadas neste estudo, denotam a expressão de oposições relacionais de base, que se manifestam por meio de antinomias a partir da elaboração de categorias marginais em oposição às sociabilidades hegemônicas de referência (Doise, 2002; Marková, 2006; Moscovici, 2003). Como também evidenciado por Curran (2016), Jovanović, Kóczé e Balogh (2015) e Oprea (2009), as dimensões encontradas no presente estudo, de classe social (exclusão social/pobreza), gênero (imagens do feminino) e etnia (elementos mágico-religosos característicos da cultura cigana), constituem categorias centrais nos processos de discriminação interseccional das mulheres ciganas, como produto da elaboração de objetos sociais nos quais se projetam as dinâmicas identitárias do temor, ameaça e clivagem social (Tileagã, 2015).

Considerando, portanto, as objetivações identificadas, o campo epistêmico de constituição das representações analisadas na ancoragem psicológica indica ainda diferentes ênfases do objeto, que também se manifestam no processo de ancoragem social (Doise, 1992): a Ciganidade, acionando significados prototípicos e de conotação negativa (Berti et al., 2013; Carvalho et al., 2012; Perez et al., 2002), e o Feminino, apoiado em ambiguidades na constituição do ser mulher no pensamento social - mãe e chefe de família, sedutora e prostituta, e ainda explorada e submissa aos homens e à cultura.

A análise do processo de ancoragem social permitiu investigar como experiências compartilhadas originam representações com dinâmica semelhante (Rimé \& Páez, 2014). A partir dos resultados encontrados, verificou-se que os homens possuem imagem mais positiva do que as mulheres, que se apresentam predominantemente associadas à imagem da cigana vidente e marginalizada. Por se tratar de um objeto que pode ativar princípios identitários (Clémence et al., 1994; Deschamps \& Moliner, 2009) em função de conter a dimensão compartilhada Ser Mulher (efeito de gênero resultando na identificação sujeito-objeto de representação), as participantes mulheres elaboraram uma imagem mais nuclear e figurativa centrada na Cigana, enquanto os homens acionaram diferentes imagens do feminino, com significados mais difusos e ambíguos acerca do objeto dimensionado Mulher.

Ainda no que concerne aos resultados relativos à ancoragem social, foi possível identificar que indivíduos que residem perto de acampamentos ciganos apresentam imagem mais negativa do que aqueles que possuem menos contato com membros dessa etnia. Carvalho et al. (2012), no Brasil, confirmam essa esfera ao demonstrar que pessoas que residem perto de territórios ciganos, ou seja, que possuem mais contato e interação com o grupo, apresentam imagem mais fortemente apoiada em estereótipos negativos do que aqueles que não vivem próximos a acampamentos ciganos. Na Itália, também Monaci e Trentin (2008) evidenciaram o efeito negativo da interação ao constatarem que os estereótipos e sentimentos em relação aos ciganos se tornaram mais negativos ao longo do período escolar em classes multiculturais com alunos ciganos e não ciganos. Os dados encontrados pelos pesquisadores sugerem que, nesse caso, o contato pode servir para fortalecer e justificar a hostilidade contra o grupo e não para sua superação, como preconizado na teoria do contato (Pettigrew \& Tropp, 2006).

A dimensão da experiência com o objeto de representação (Jodelet, 2015) pode ser ainda um fator interveniente nos dados referentes à nacionalidade, apoiada na história de relação entre os grupos: brasileiros apresentaram imagem mais positiva (porém romantizada) do que os italianos e ligada à figura da cigana quiromante e vidente. De fato, os brasileiros estão mais vinculados aos significados de cunho mágico-religioso (Cluster 8 Vidente), apresentando uma imagem mais abstrata do objeto, talvez em função do pouco 
contato e das imagens difundidas nas novelas e romances brasileiros (Teixeira, 2008). Os italianos, por sua vez, estão mais centrados nas diferentes concepções de mulher (Clusters 1 Mulher pobre, 2 Mulher submissa e 5 Mulher malvada) e em elementos de conotação negativa e que ilustram a marginalização sofrida. Se, no Brasil, as imagens difundidas sobre os ciganos se apoiaram também na ficção das histórias e novelas; na Itália, são os jornais os principais veículos de informação responsáveis pela propagação de significados sobre eles, retratando os conflitos e dilemas do cotidiano desse grupo e da sua interação com a sociedade local (Sigona, 2006).

Tendo em vista que a experiência com o objeto social (Jodelet, 2015; Moscovici, 2003) orienta tomadas de posição dos sujeitos da representação frente aos ciganos, como evidenciado de maneira transversal na análise do processo de ancoragem social por meio das variáveis sexo, contato e nacionalidade, essa dimensão pode ser considerada um princípio organizador das representações sociais de ciganos (Lima et al., 2016). Esse dado sugere que práticas interventivas para redução do preconceito precisam alinharse com correções de assimetrias sociais e implementação de políticas públicas que promovam, efetivamente, a acessibilidade dos grupos ciganos aos recursos simbólicos e materiais, realidade ainda distante frente ao diagnóstico da questão cigana em diferentes nacionalidades (Pérez, Moscovici, \& Chulvi, 2002; Ram, 2014; Ravnbøl, 2010).

Sobre a dinâmica e função dos significados encontrados neste estudo, os resultados corroboram as reflexões de Moscovici (2011) sobre as ambiguidades presentes no modo como os ciganos foram historicamente representados ao longo dos últimos quatro séculos: se por um lado acionam tomadas de posição favoráveis no que se refere à imagem da liberdade, da alegria e da música; por outro, assumem no pensamento social a condição de eternos estrangeiros, ladrões e delinquentes (Carvalho et al., 2012; Magano \& Mendes, 2014; Mendes, 2015). Sob a marca da ideologização do povo cigano como objeto social que ainda permanece no universo da não familiaridade (Moscovici, 2009; Pérez et al., 2002), o preconceito e a discriminação constituem um dos maiores obstáculos dos diferentes segmentos ciganos na atualidade, e a mulher cigana, representando o cigano na generalidade, um dos principais alvos dessa discriminação.

Como produto da cultura, ancoradas em escolhas históricas que envolvem relações de conflito e de interesses segundo as ideologias vigentes, as representações sociais podem atuar como "gaiolas mentais", dificultando processos de atualização dos objetos sociais no pensamento social, o que denota a importância de desenvolvimento de estudos nessa esfera para fins de proposição de novas práticas sociais. Investigações, portanto, alinhadas a esse propósito podem fornecer importantes contribuições à análise de processos que integrem as macro-produções sociais às práticas cotidianas dos indivíduos e grupos sociais, permitindo, assim, pensar estratégias de intervenção em construções psicossociais como o preconceito e a discriminação social. Essa implicação prática coaduna demandas em pauta quando se discute a questão da ausência de políticas públicas voltadas aos direitos e demandas do povo cigano, bem como revela um longo caminho a ser trilhado tanto no âmbito da elaboração de programas sociais e políticas públicas pró-ciganas quanto de mudança social nas relações cotidianas entre ciganos e não ciganos (Brasil, 2013).

Sobre as limitações do estudo, a composição da amostra direcionada apenas a estudantes universitários impossibilita a generalização das análises e resultados para outros contextos e arranjos de produção das representações sociais identificadas. Apesar disso, os resultados encontrados a partir da amostra de universitários podem fornecer importantes contribuições justamente por sinalizar implicações práticas para o desenvolvimento de atividades de formação direcionadas a futuros profissionais que poderão trabalhar em contextos de inserção do povo cigano.

\section{Referências}

Almeida, A. M. O. (2009). Abordagem societal das representações sociais. Sociedade e Estado, 24(3), 713-737. doi: 10.1590/ S0102-69922009000300005

Berti, C., Pivetti, M., \& Di Battista, S. (2013). The ontologization of Romani: An italian study on the cross-categorization approach. International Journal of Intercultural Relations, 37(4), 405414. doi:10.1016/j.ijintrel.2013.03.002

Bonomo, M., Souza, L., Melotti, G., \& Palmonari, A. (2013). Princípios organizadores das representações de rural e cidade. Sociedade e Estado, 28(1), 91-118. doi: 10.1590/S010269922013000100006

Bonomo, M., Souza, L., Trindade, Z. A., Canal, F. D., Brasil, J., Livramento, A. M., \& Patrocínio, A. P. S. M. (2011). Mulheres ciganas: Medo, relações intergrupais e confrontos identitários. Universitas Psychologica, 10(3), 745-758.

Brasil - Secretaria de Políticas de Promoção da Igualdade Racial. (2013). Brasil cigano - Relatório Executivo I semana nacional dos povos ciganos. Retrieved from http://www.seppir.gov.br/ comunidades-tradicionais/relatorio-executivo-brasil-cigano. pdf

Carvalho, N. C., Lima, M. E. O., Faro, A., \& Silva, C. A. F. (2012). Representações sociais dos ciganos em Sergipe: Contato e estereótipos. Psicologia e Saber Social, 1(2), 232-244.

Ceneda, S. (2002). Romani women from central and eastern europe: A 'fourth world', or experience of multiple discrimination. Czech Republic/Poland/Romania: Asylum Aid.

Clémence, A., Doise, W., \& Lorenzi-Cioldi, F. (1994). Prises de position et principes organisateurs des représentations sociales. In C. Guimelli (Ed.), Structures et transformations des représentations sociales (pp. 119-152). Neufchâtel, Suisse: Delachaux et Niestlé.

Curran, S. (2016). Intersectionality and human rights law: An examination of the coercive sterilisations of romani women. In The Equal Rights Review (pp. 132 - 159). Londres: Equal Rights Trust.

Deschamps, J-C., \& Moliner, P. (2009). A identidade em psicologia social-Dos processos identitários às representações sociais. Petrópolis, RJ: Editora Vozes.

Doise, W. (1982). L'explication en psychologie sociale. Paris: PUF (Presses Universitaires de France).

Doise, W. (1992). L'ancrage dans les études sur les représentations sociales. Bulletin de Psychologie, 45, 189-195.

Doise, W. (2002). La forza delle idee. Bologna: Il Mulino. 
Doise, W. (2011). Sistema e metasistema. In A. M. O. Almeida, M. F. S. Santos, \& Z. A. Trindade (Eds.), Teoria das representações sociais: 50 anos (pp. 123-156). Brasília: Technopolitik.

Doise, W., Clemence, A., \& Lorenzi-Cioldi, F. (1992). Représentations sociales et analyses de données. Grenoble: PUG (Presses Universitaires de Grenoble).

Grabovschi, C. (2011). L'étude des représentations sociales de l'alimentation: Une approche développementale intégrative. Revista Educação e Cultura Contemporânea, 8(16), 1-20.

Hancock, I. (2008). The "gypsy" stereotype and the sexualization of romani women. In V. Glajar \& D. Radulescu (Orgs.), "Gypsies" in european literature and culture (pp. 181-191). New York: Palgrave Macmillan.

Jodelet, D. (1999). Os processos psicossociais da exclusão. In B. B. Sawaia (Org.), As artimanhas da exclusão: Análise psicossocial e ética da desigualdade social (pp. 53-66). Petrópolis: Vozes.

Jodelet, D. (2015). Représentations sociales et mondes de vie (Textes édités par N. Kalampalikis). Paris: Editions des Archives Contemporaines.

Jovanović, J., Kóczé, A., \& Balogh, L. (2015). Intersections of gender, ethnicity, and class: History and future of the romani women's movement. Budapest: Central European University.

Laszlo, J. (1997). Narrative organisation of social representations. Papers on Social Representations, 6(2), 155-172.

Lebart, L., Morineau, A., Becue, M., \& Haeusler, L. (1994). SPAD-T - Manuel de l'utilisateur. Saint-Mondé, France: Cisia - Centre International de statistique et d'informatique appliquées.

Lermo, J., Román, J., Marrodán, M.D., \& Mesa, M.S. (2006). Modelos de distribución de apellidos en la población gitana española. Antropo, 13, 69-87.

Lima, M. E. O., Faro, A., \& Santos, M. R. (2016). A desumanização presente nos estereótipos de índios e ciganos. Psicologia: Teoria e Pesquisa, 32(1), 219-228. doi: 10.1590/010237722016012053219228

Magano, O., \& Mendes, M. M. (2014). Mulheres ciganas na sociedade portuguesa: Tracejando percursos de vida singulares e plurais. Revista Sures, 3, 1-15.

Marková, I. (2000). Des thêmata de base des représentations sociales du SIDA. In C. Garnier (Ed.), Les formes de la pensée sociale (pp. 55-77). Paris: Presses Universitaires de France.

Marková, I. (2006). Dialogicidade e representações sociais - As dinâmicas da mente. Petrópolis: Editora Vozes.

Mendes, M. M. (2015). Nos interstícios das sociedades plurais e desigualitárias: a situação social dos ciganos. In E. Martins, R. Fernandes, \& S. Fonseca (Coords.), Modelos e projetos de inclusão social (pp. 32-41). Viseu: Escola Superior de Educação de Viseu.
Monacelli, N., Molinari, L., \& Emiliani, F. (2007). Cerner les similitudes, composer avec les différences. Les droits de l'enfant en Italie et en Jordanie. Les Cahiers Internationaux de Psychologie Sociale, 1(73), 47-59. doi: 10.3917/cips.73.0047

Monaci, M. G., \& Trentin, R. (2008). Gli alunni rom/sinti nella scuola media: Effetti del contatto sull'atteggiamento etnico nelle classi multiculturali. Giornale Italiano di Psicologia, 4, 933-960. doi: $10.1421 / 28424$

Moonen, F. (2011). Anticiganismo na Europa e no Brasil. Edição 3, digital revista e atualizada. Recife: Núcleo de Estudos Ciganos.

Moscovici, S. (2003). Representações sociais - Investigações em psicologia social. Petrópolis: Vozes.

Moscovici, S. (2009). Os ciganos entre perseguição e emancipação. Sociedade e Estado, 24(3), 653-678.

Moscovici, S. (2011). An essay on social representations and ethnic minorities. Social Science Information, 50, 442-461. doi: $10.1177 / 0539018411411027$

Oprea, A. (2009). Intersectionality backlash: A romani feminist's response. Budapest: European Roma Rights Centre.

Pérez, J. A., Moscovici, S., \& Chulvi, B. (2002). Natura y cultura como principio de clasificación social - Anclaje de representaciones sociales sobre minorías étnicas. Revista de Psicología Social, 17(1), 51-67.

Pettigrew, T. F., \& Tropp, L. R. (2006). A meta-analytic test of intergroup contact theory. Journal of Personality and Social Psychology, 90(5), 751-783. doi: 10.1037/0022-3514.90.5.751

Ram, M. H. (2014). Europeanized hypocrisy: Roma inclusion and exclusion in central and eastern Europe. Journal on Ethnopolitics and Minority Issues in Europe, 3(13), 15-44.

Rateau, P. (2004). Organizing principles and central core of social representations empirical hypothesis. Arquivos Brasileiros de Psicologia, 56(1), 82-92.

Ravnbøl, C. I. (2010). The human rights of minority women: Romani women's rights from a perspective on international human rights law and politics. International Journal on Minority and Group Rights, 17, 1-45. doi: 10.1163/15718111 0X12595859744123

Rimé, B., \& Páez, D. (2014). Eventi emozionali collettivi e rappresentazioni sociali. In A. Palmonari \& F. Emiliani (Eds.), Psicologia delle rappresentazioni sociali (pp. 95-122). Bologna: Il Mulino.

Shiraev, E. B., \& Levy, D. (2015). Cross-cultural psychology: Critical thinking and contemporary applications. Routledge.

Sigona, N. (2006). Country profile. In N. Sigona (Coord.), Political participation and media representation of Roma and sinti in Italy (pp. 5 - 8). Firenze: OsservAzione.

Teixeira, R. C. (2008). História dos ciganos no Brasil. Recife: Núcleo de Estudos Ciganos.

Tileagã, C. (2015). The nature of prejudice: Society, discrimination and moral exclusion. Abingdon: Routledge.

Recebido em 25.05.2016

Primeira decisão editorial em 06.01.2017

Versão final em 10.02.2017

Aceito em 24.02.2017 